\title{
Social representations theory: An approach to studying translators' socio-cognitive processes
}

\author{
Sari Hokkanen \\ Tampere University, Finland \\ sari.hokkanen@tuni.fi \\ https://orcid.org/0000-0002-0477-7023
}

\begin{abstract}
Social Representations Theory provides a comprehensive theoretical model for researching translators' socio-cognitive processes. Developed in social psychology in the 1960s, the theory offers an integrative view of both individual and social processes in the construction and reconstruction of knowledge. It draws attention to embodied meaning-making and the effect of material surroundings in perpetuating and disseminating social representations. Importantly, Social Representations Theory does not see representations as individual, solely conscious, or static mental constructions but as dynamic social-psychological phenomena that are enacted in discourse and social interaction. This article discusses Social Representations Theory as an approach to the empirical study of translators' cognitive processes. Introducing the main concepts of the theory and using translators' conceptualizations of source-text authors and target-text readers as an example, the article suggests avenues for using the theory in Cognitive Translation Studies.
\end{abstract}

Keywords: Social Representations Theory; cognition; Cognitive Translation Studies; social psychology

\section{Introduction}

This article introduces Social Representations Theory as a potential theoretical model for studying socio-cognitive aspects of translation. Since its inception in French social psychology in the 1960s (Moscovici, 1961/2008), it has been widely used in the social sciences (Duveen, 2000; Flick \& Foster, 2008; Sammut et al., 2015). At its core, Social Representations Theory seeks to explain "the processes through which knowledge is generated, transformed and projected into the social world" (Duveen, 2000, p. 2). The theory is not tied to any specific method; rather, studies in this field often make use of a variety of methodological approaches as demanded by the research problem at hand (Flick et al., 2015). For example, Moscovici's seminal work (1961/2008) included complex sampling methods, interviews, questionnaires, and the thematic analysis of journalistic texts. In this paper, a social representation is not defined as a static mental construction held by individuals but as: 
Hokkanen, S. (2020). Social representations theory: An approach to studying translators' sociocognitive processes. Linguistica Antverpiensia, New Series: Themes in Translation Studies, 19, 94-110.

system(s) of values, ideas and practices with a two-fold function; first, to establish an order which will enable individuals to orientate themselves in their material and social world and to master it; and secondly to enable communication to take place among the members of a community by providing them with a code for social exchange and a code for naming and classifying unambiguously the various aspects of their world and their individual and group history. (Moscovici, 1973, p. xiii)

This definition highlights the role of social representations in enabling us to understand and function in the social world and also to communicate with others. In short, social representations are "ways of world making" (Moscovici, 1988, p. 231) where thoughts, affects, and discourse construct the social world we live in, along with its material, cultural, political, and ideological realities.

By examining the key concepts of Social Representations Theory and applying them to one aspect of translators' cognitive processing, I propose a theoretical approach to the study of translation that effectively combines individual, interindividual, and social aspects of translation cognition. The main strength of the theory is the way it connects individual cognitive processes and social processes and offers the researcher "an effortless transition" between the two (Wagner, 2015, p. 27). Instead of treating cognitive and social processes as separate entities or as one embedded in the other, as is often the case with traditional models in Translation Studies (see Muñoz Martín, 2016), Social Representations Theory views the two as inseparable. The theory, I argue, therefore fits in well with the current situated and embodied approaches to cognition in translation studies.

Originating in social psychology, Social Representations Theory asserts that there is no clear break between an individual mind and its social and material environment, but that human cognition is fundamentally social and relational (Moscovici, 1961/2008, 1984). The theory may further develop the field of Cognitive Translation Studies because it directs attention away both from treating a translator's cognition as an individual "black box" disconnected from affective, embodied, material, and social realities (see Jodelet, 1989/1991), and from treating cognitive processes in isolation from historical developments, in terms of individuals' life histories and cultural change (Moscovici 1984). Therefore, Social Representations Theory may assist the field of Cognitive Translation Studies in further integrating cognition and culture.

To my knowledge, Social Representations Theory has been applied at least once previously in Translation and Interpreting Studies. Leanza et al. (2017) used the theory in an examination of Canadian physicians' conceptualizations of working with public-service interpreters. The study included focus group interviews with physicians in three different career stages $(n=98)$ and traced the influence of professional development and work experience on their social representations. The representations of third-year medical students were more unstructured and reflected ideals expounded in their education, whereas senior physicians expressed a more nuanced understanding that reflected their own need to be in control of the medical consultation-and, consequently, of the interpreter. This study points to an important aspect of translators' and interpreters' cognitive processes: their work is affected not only by their own cognition but by that of other professionals working with them. 
Hokkanen, S. (2020). Social representations theory: An approach to studying translators' sociocognitive processes. Linguistica Antverpiensia, New Series: Themes in Translation Studies, 19, 94-110.

The aim of this article is to discuss the core elements of Social Representations Theory and suggest ways in which it could be applied to the study of translators' socio-cognitive processes. As an example, I examine the way in which the translator's conceptualizations of source-text (ST) authors and target-text (TT) readers could be studied empirically through the lens of the theory. It has been called a near-truism in our field that translators should think about their readers when translating (Suojanen et al., 2015), and the importance of thinking about both the ST authors and the future recipients of the translation is a core element of many established translation theories, such as functionalism (e.g., Nord, 2012).

Despite this seemingly widespread consensus and despite repeated calls for the use of empirical evidence to support translators' conceptualizations of especially their readers (e.g., Jääskeläinen, 2012; Kruger \& Kruger, 2017; Suojanen et al., 2015), there seems to be a lack of theoretical explanations for the conceptualization process itself (Nord, 2012). Social Representations Theory, I suggest, would offer such a theoretical explanation and an avenue for the empirical study of this and other socio-cognitive processes related to translation.

In this article, I first explain the key concepts of the theory in Sections 2 and 3. While focusing on theoretical questions, the article also suggests methods for studying social representations in Section 4, which relates the key concepts of the theory to translators' socio-cognitive processes. Conclusions are provided in Section 5.

\section{Basic concepts of Social Representations Theory}

According to Moscovici (1984), "the purpose of all representations is to make something unfamiliar, or unfamiliarity itself, familiar" (p. 24). This means that we need existing categories and points of reference that we have come across in interaction with other people and the material world in order to connect new things with previous knowledge. To this end, we make use of two mechanisms, anchoring and objectification.

\subsection{Anchoring}

Anchoring refers to the cognitive process of connecting new phenomena to existing, socially derived and socially shared structures of knowledge. In this process, we compare a new object or idea to an existing category; we "anchor" it to a familiar context in order to make sense of it (Moscovici, 1984). Through the process of anchoring, "one copes with the complexity of the world by grouping events and objects together and treating them as similar or equivalent" (Marková, 1996, p. 187). Whereas such processes of categorization may be approached as purely cognitive information processing that occurs inside an individual brain, the process of anchoring in Social Representations Theory is decidedly social. This is because the categories and classifications available to individuals are derived from "everyday communications and [are] accepted and conventionalized in the social or cultural context" (Flick, 1995, p. 76). Indeed, according to the theory and to social psychology in general, whatever we perceive as reality refers to and originates in specific social contexts (Carugati, 1990). For the human agent, there are no objective "facts" outside of the social world, only socially situated knowledge. 
Hokkanen, S. (2020). Social representations theory: An approach to studying translators' sociocognitive processes. Linguistica Antverpiensia, New Series: Themes in Translation Studies, 19, 94-110.

In addition to categorizing, the anchoring process also entails naming, and here the social character of anchoring is highlighted further. When we give a name to an object, we aim to bring clarity to an otherwise ambiguous and inchoate experience of the world (Moscovici, 1984). Individuals rarely assign names to objects in isolation from pre-existing networks of meaning and social understandings, however. Others must be able to understand the name we use for an object, even if they contest our choices-which also makes the process of naming dependent on social negotiation. Indeed, assigning a name to a thing gives it a socially accessible meaning (Moscovici, 1984).

Moreover, the process of naming is not a value-free activity. Rather, it reflects social attitudes and is closely related to political and ideological realities (Moscovici, 1984). For example, the words we use to refer to marginal or stigmatized groups may reveal and perpetuate social inequality (Marková, 1996). This is because social representations are not only knowledge "'about something'; they are also expressive of how communities hand down, sustain and negotiate their cultural identities, ways of life and strategies for survival and living" (Campbell \& Jovchelovitch, 2000, p. 265).

Because of this value-laden character of the anchoring process, social representations activated in points of contact between cultures are especially at risk of generating or perpetuating harmful cultural stereotypes. This risk may be useful for us to bear in mind since translation and interpreting are inherently cross-cultural activities. As pointed out by Marková (2012), categorization is a fundamental cognitive process, but it has been seen in sociopsychological literature as the main mechanism underlying prejudice, racism, and discrimination. However, an encounter between knowledge systems always has the potential to lead to either dialogical or non-dialogical outcomes (Jovchelovitch, 2007, Chapter 5). As Jovchelovitch argues, these outcomes are dependent on the cognitive processes of perspective-taking and recognition of the legitimacy of different knowledge systems, on the one hand, and on the social processes related to hierarchies and power differentials between the knowledge systems in question, on the other. Cultural stereotyping in relation to translation is discussed further in Section 4.

\subsection{Objectification}

Another important mechanism in the formation of social representations is that of objectification. Similarly to anchoring, objectification also aims to make the world more understandable by allowing us to connect unfamiliar phenomena to something we already know. In objectification, abstract and complex ideas are shaped into concrete objects or images, therefore making these ideas "almost tangible" (Moscovici, 1984, p. 29). Through the process of objectification, we create iconic images, tropes, and symbols to rely on, as a shorthand, instead of processing complex concepts. For example, images of polar bears on melting ice come to represent climate change (Smith \& Joffe, 2009) or the computer becomes a metaphor explaining human cognition (Moscovici, 1988).

Often, the core of a social representation is a web of interrelated images or metaphors, which is sometimes called a "figurative nucleus" (Moscovici, 1984, pp. 38-39). This image structure 
Hokkanen, S. (2020). Social representations theory: An approach to studying translators' sociocognitive processes. Linguistica Antverpiensia, New Series: Themes in Translation Studies, 19, 94-110.

"captures the essence of the phenomenon, makes it intelligible for people and weaves it into the fabric of the group's common sense" (Wagner et al., 1999, p. 99). As the metaphor of a computer for human cognition makes clear, however, this "essence" of the phenomenon is not contingent on any relationship between the metaphor and reality, and the social representation may endure even after it has been disproven by research.

The attribution of images and metaphors to a phenomenon is neither random nor subjective but contingent on the social group in question and its immediate life world (Wagner et al., 1999; see also Lakoff \& Johnson, 1980). For example, in a classic study in the literature on social representations, Jodelet (1989/1991) discovered that the social representations held by villagers in the French countryside about mental health outpatients living among them as lodgers made extensive use of metaphors that were related to farming. The images at the core of the villagers' social representation of mental illness included going sour like milk, which for them signified decay.

The images used by social groups in the process of objectification may not have to be intellectually familiar; they may also be familiar to us as bodily experiences (Wagner, 2015, 2017; see also O'Connor, 2017). When discussing the difference between languages, for instance, we use the experience of physical distance and proximity as we talk about "distant" languages that may be difficult to translate. We also often conceptualize the translation strategies of domestication and foreignization in terms of a physical distance that either the reader or the writer must traverse-an image originating from Schleiermacher-even though we could also conceptualize these strategies in other ways, such as affective familiarity (Koskinen, 2012). The mechanism of objectification may, therefore, link Social Representations Theory to embodied cognition and other approaches foregrounding the significance of embodiment in social meaning-making (O'Connor, 2017; Wagner, 2017; see also Barsalou, 1999; Gibbs, 2005).

Objectification frequently makes people unaware of social representations. When a complex idea becomes simplified in a figurative form, the notion becomes more automatic, "[sinking] under the level of awareness" and eventually "incorporated into the symbolic social environment" such as in works of art or physical objects (Marková, 1996, p. 187). The representation will then perpetuate itself through individuals' unconscious activities in that environment (see, e.g., Section 3.3 on restroom arrangements and social representations of gender). Social representations or their figurative nuclei should not, in other words, be understood as explicit, fully conscious mental representations or mental images; rather, the theory takes into account the fact that much of our mental processing is unconscious (see, e.g., Barsalou, 1999; Clark \& Chalmers, 1998).

These largely unconscious images and metaphors, often derived from embodied experiences, seem to be compatible with more recent understandings of the role of perceptual symbols (Barsalou, 1999), metaphors (e.g., Lakoff \& Johnson, 1980), and embodiment in cognition (e.g., Gibbs, 2005). All cognition-even conceptual knowledge-works through perceptual symbols, or a subset of the neural activation that occurs during perception (Barsalou, 1999). This is not to say that these perceptual symbols were static mental images that we experience 
Hokkanen, S. (2020). Social representations theory: An approach to studying translators' sociocognitive processes. Linguistica Antverpiensia, New Series: Themes in Translation Studies, 19, 94-110.

consciously. They rather function as unconscious neural representations of sensory-motor experiences (Barsalou, 1999). In a similar vein, Lakoff and Johnson (1980) posit that basic embodied experiences of spatiality structure most of our fundamental concepts. They also argue that the ability to turn human experience into a metaphor of something concretesuch as in the process of objectification -is a necessity for us to deal with these experiences rationally. Furthermore, as Gibbs (2005) claims, the basis of cognition is not only in embodied experiences, but in phenomenological experiences of the body in action: even perception is not a passive, internal reconstruction of external stimuli, but "an act of the whole animal, the act of perceptually guided exploration of the environment" (p. 43). The role of embodied action in the formation of social representations is discussed further in Section 3.1.

\section{The processes of social representation}

This section introduces three processes by which social representations are generated and transformed: socio-, onto-, and microgenesis. An explanation of these three processes helps to clarify the different levels at which social representations may be examined: the social group, the individual, and interindividual interaction.

\subsection{Sociogenesis}

Sociogenesis refers to the generation of social representations at the level of social groups (Duveen \& Lloyd, 1990). At this level, the social group is taken as the main analytic category. A sociogenetic approach to social representations therefore examines how certain phenomena are understood in a social group and how the understanding is distributed in that group and transformed over time (Duveen \& Lloyd, 1990). As illustrated by Moscovici's original study on the ways the French public understood and felt about psychoanalysis in the 1960s, social representations are rarely distributed evenly within social groups and cultures, but different representations may exist concurrently and generate negotiation, debate, and even conflict (Moscovici, 1961/2008).

This multiplicity of representations is captured well in the concept of cognitive polyphasia. This refers to the ability of social groups (but also of individuals) to use "different logical registers" to explain and make sense of the world in a way that even mutually exclusive or contradictory logical registers share a "dynamic coexistence" (Moscovici, 1961/2008, p. 180). In Moscovici's original study, these logical registers refer mainly to different kinds of folk knowledge, on the one hand, and scientific theories, on the other. In addition to different logics or modes of thinking (e.g., religion vs. science), the multiplicity of social representations evident in cognitive polyphasia may also relate to the actual content of the representation (e.g., illness is a curse vs. illness is a medical phenomenon) or to the affects raised by the representation (e.g., fear of vs. empathy towards the mentally ill; Jovchelovitch \& PriegoHernández, 2015). Cognitive polyphasia is a natural consequence of human life since different groups of people "produce different representations, symbols and narratives about what is real" (p. 163) and since people simultaneously possess multiple social identities and inhabit multiple social worlds. Nevertheless, cognitive polyphasia does not mean that different modes of explanation would be treated equally-political and cultural circumstances often 
Hokkanen, S. (2020). Social representations theory: An approach to studying translators' sociocognitive processes. Linguistica Antverpiensia, New Series: Themes in Translation Studies, 19, 94-110.

bestow more power on certain registers and suppress or marginalize others (Jovchelovitch \& Priego-Hernández, 2015).

\subsection{Ontogenesis}

A researcher of social representations may also take the individual as an analytic category, although not in isolation from the sociogenetic perspective. This individual view has been called the ontogenetic level (Duveen \& Lloyd, 1990). Ontogenesis concerns the process by which individuals gain access to surrounding social representations and reconstruct these social representations for themselves. This process is most visible in the development of children who grow up in a specific environment of social representations and acquire the competence to participate in that environment (Duveen \& Lloyd, 1990; Moscovici, 1984). However, ontogenesis is not restricted to children's development but continues throughout a person's lifecycle, as individuals enter new social groups or encounter new social representations in their existing social environment (Duveen \& Lloyd, 1990). Besides childhood, professional development is a particularly active time in the construction and reconstruction of social representations at the ontogenetic level. For example, translation instructors often encourage students new to the field to approach a ST in a particular way, therefore fostering a specific professional vision (Goodwin, 1994) regarding texts. One element in this vision is seeing a piece of writing as representative of a certain genre instead of an isolated linguistic expression, therefore necessitating research on typical features of that genre as part of the translation task.

Cognitive polyphasia may also be observed at the ontogenetic level, and it aptly illustrates the interconnectivity of sociogenesis and ontogenesis. Because different modes of thinking and conceptualizing the world are prevalent in different social groups and because individuals are members of several social groups simultaneously, they have multiple logical registers at their disposal to make sense of any given social object. As Wagner et al. (2000) argue, each social world "requires its own distinct form of discourse and thought" (p. 303); but even contradictory conceptualizations are usually not problematic if they are not verbalized in the same discussion with the same participants. Rather, when people anchor a new phenomenon, they typically draw on different forms of thought depending on the social situation at hand. Cognitive polyphasia at the individual level is therefore a typical aspect of human life, but something we only occasionally realize about ourselves: "the cognitive contradiction between ... representational fields is probably only felt when attention is explicitly directed towards it" (p. 311).

\subsection{Microgenesis}

Both sociogenesis and ontogenesis are made possible through microgenesis, described as the motor driving the two, and it refers to the evocation and processing of social representations in interaction and communication (Duveen \& Lloyd, 1990; Wagner, 2015). Through the course of social interaction, people negotiate social identities and establish mutual frames of reference, and they do so by drawing on social representations (Duveen \& Lloyd, 1990; Moscovici, 1961/2008). The microgenetic process functions as a motor for sociogenesis in the 
Hokkanen, S. (2020). Social representations theory: An approach to studying translators' sociocognitive processes. Linguistica Antverpiensia, New Series: Themes in Translation Studies, 19, 94-110.

sense that communication helps disseminate certain social representations in the social group, be it via face-to-face or media communications (Duveen \& Lloyd, 1990; see also Smith \& Joffe, 2009). Conversely, the microgenetic process also functions as a motor for ontogenesis in the sense that communication is the means by which individuals come in contact with social representations prevalent in their social groups (see also Jovchelovitch, 2007). However, the ontogenetic changes taking place in interaction may be transitory and strategic rather than permanent and ontological, helping individuals to pursue certain communicative and interactional goals rather than altering their perception of reality (Duveen \& Lloyd, 1990; Wagner, 2015).

However, not all social representations are distributed through language and discourse; microgenesis entails not only verbal communication but also embodied action (Wagner, 2015, 2017). This is because "the social world exists before and initially independent of an individual" and "he or she inadvertently has to interact with the existing objects and issues in order to get a 'feeling' for the world's constitution" (Wagner, 2015, p. 20; see also Gibbs, 2005). Therefore, by navigating our material and social surroundings, we are subjected to existing social representations. For example, social representations of gender are often reflected in public restroom arrangements, and the way the physical environments guide individuals' actions forces them to enact these representations-and we sometimes become aware of this only if the social representations in the material arrangements disagree with our own.

The processes of sociogenesis, ontogenesis, and microgenesis illuminate different aspects of the formation and transformation of social representations, but they are fundamentally intertwined. This offers a framework for empirical research designs that aim to tackle issues related to socially situated cognition. Many studies on social representations are based on an "epistemology of interaction" (Marková, 2012, p. 12), in which the lives of social groups are seen as linked to their cultural, historical, and political surroundings through interaction, and this link, in turn, is seen as providing "meaning and structure to the mind and society" (see also Gillespie, 2012). Furthermore, Wagner (2015) argues that the link created by interaction between the individual and the social context yields Social Representations Theory its comprehensive nature:

Due to its overarching character, the concept of social representations allows for an effortless transition from the individual level to the collective level: on the one hand we have individuals with their motivations, beliefs, knowledge and affiliation preferences that entail a person's actions; on the other hand, individuals in concert enact social representations, the pattern of which constitutes what we call social reality. Thus, the two conceptual levels are linked by [bodily] action. (pp. 27-28) 
Hokkanen, S. (2020). Social representations theory: An approach to studying translators' sociocognitive processes. Linguistica Antverpiensia, New Series: Themes in Translation Studies, 19, 94-110.

\section{In the study of translators' socio-cognitive processes}

In this section, I suggest ways in which Social Representations Theory could be applied to empirical studies of translators' socio-cognitive processes. As an example, I take translators' conceptualizations of ST authors and TT readers. The suggestions are structured according to the key concepts of the theory introduced above.

\subsection{Anchoring and objectification}

When translators encounter a new translation task, how do they conceptualize the ST authors and the TT readers? And how could we study this conceptualization? To begin with the process of anchoring, a first step would be to examine which sources of existing knowledge the translator relies on. For example, the translator may research the author or the corporate body or institution that produced the ST. The information obtained in this manner would help the translator to connect the ST author to their existing knowledge about the world; if the author turns out to be a journalist working for a British lifestyle magazine, what existing notions of journalists, lifestyle magazines, or British people will become relevant for the translator in interpreting the ST? In addition to explicit research, translators may also rely on other sources that help them to anchor aspects of the unfamiliar ST author to existing knowledge. These may include translator training and education, previous work assignments, popular culture, personal relationships, or any other aspect of their lived experience. All of this also applies to their conceptualization of the TT readers.

These anchors to existing social representations could be elicited through think-aloud protocols where the translator is asked to verbalize their thinking process, through interviews that include direct questions about the translator's conceptualizations, or through textual analysis, where both the ST and the translation are examined for traces revealing the translator's conceptualization of the authors. It may be assumed that none of these methods alone would provide a comprehensive understanding of the translator's anchoring process, but together they may begin to shed some light on the phenomenon.

Moving on to the process of objectification inherent in the formation of social representations, it can be hypothesized that translators may-at times, at least, and not always consciously-create a visual image of their ST authors or TT readers. While there do not seem to be empirical studies as yet verifying that such (conscious) image-forming processes would indeed take place, the phenomenon seems to be recognized in pedagogically oriented Translation Studies literature. One explicit approach to creating a visual image of TT readers is presented in the User-Centred Translation (UCT) approach put forward by Suojanen et al. (2015). Their UCT model specifies the explicit construction of mental models about TT readers as one step towards usable translations (pp. 4-6). Among several suggested methods for constructing these mental models, they describe personas, which lean heavily on visual imagery. Personas are fictive, archetypal characters that the translator creates after acquiring empirical information about the translation's future audience(s) (p. 70). A persona usually consists of personal details about the fictive archetypal TT reader and a photograph or a drawing. Suojanen et al. (2015) suggest that one strength of this method is its intuitiveness 
Hokkanen, S. (2020). Social representations theory: An approach to studying translators' sociocognitive processes. Linguistica Antverpiensia, New Series: Themes in Translation Studies, 19, 94-110.

regarding translators' usual work processes: "it is common for translators to imagine what the readers of their translations are like" (p. 71).

Personas are, then, one method with which trainee translators are explicitly taught to conceptualize TT readers, but the method could also be used to study the objectification process and potential cultural stereotypes among translators. As discussed in Section 2.1, categorization processes related to anchoring can be linked to harmful stereotyping, and it may be relevant to professionals working in cross-cultural communication to be become more aware of this risk. Personas prompt participants to evoke certain social categories based on a real or hypothetical translation assignment. After participants have generated a persona for an ST author or a TT reader, it could be discussed further in focus groups, which may provide not only additional insight into the participants' anchoring processes but also evidence of the images they use to conceptualize authors or readers - and the extent to which these reflect cultural stereotypes. It might also prove illuminating to ask the participants to produce personas after they have completed a translation task. In this case, textual analysis could be combined with the persona task and subsequent interviews with the participants. The interview or focus-group situation may guide the participants to reflect further on and to verbalize their conceptualizations. This may indicate potential cases of cognitive polyphasia or bring to light previously unconscious or implicit images and categories (see Wagner et al., 2000).

To summarize, an empirical research agenda informed by Social Representations Theory and taking into account the processes of anchoring and objectification could expand our knowledge of

- the sources of knowledge and experience that translators use to connect ST authors and TT readers to existing categories;

- the extent to which translators construct explicit visual images of ST authors and TT readers; and

- how accurate or useful their constructions are and whether they have an effect on the translations they produce.

Importantly, the theory would contribute to these lines of enquiry by including social and situated perspectives-instead of seeing these conceptualizations as individual cognitive functions, they would be seen as socially and historically constructed. This applies not only to the content of the social representations of certain ST authors or TT readers, but also to the techniques of producing such conceptualizations, which can be seen in the working methods that translators adopt in their professional socialization process. This interplay between individuals and social groups in social representations processes is examined in more depth in the following section.

\subsection{Sociogenesis, ontogenesis, and microgenesis}

How might sociogenetic, ontogenetic, and microgenetic processes be examined in the study of translators' socio-cognitive processes and, specifically, of their conceptualizations of ST 
Hokkanen, S. (2020). Social representations theory: An approach to studying translators' sociocognitive processes. Linguistica Antverpiensia, New Series: Themes in Translation Studies, 19, 94-110.

authors and TT readers? To begin with sociogenesis, empirical applications of Social Representations Theory in Cognitive Translation Studies could examine the distribution of these conceptualizations in the profession, potentially creating comparisons between professional and non-professional translators (however they might be defined), between translators and other writing professionals such as technical writers, or between translators and interpreters. These and other comparisons would help to elucidate the distinct characteristics of the ways in which translators as a social group construct and uphold certain social representations. In addition, the distribution of certain social representations among translators could possibly reveal differences between sub-groups-for instance, between translators with different working languages or educational backgrounds or between those working in different professional or cultural contexts. Such research could be conducted through individual or focus-group interviews or surveys, even though the study of social representations is not usually carried out with exclusively quantitative methods (Flick \& Foster, 2008; Moscovici, 1961/2008).

The distribution of the social representations of ST authors and TT readers among translators could also be studied by focusing on sites of professional development. For example, translator training and education may be assumed to actively propagate preferred or accepted social representations relevant to the profession. To take an anecdotal example from personal experience, my own translator training included memorable classroom discussions about $T T$ readers that also highlight some of the negative aspects of social representations regarding the harmful stereotypes discussed earlier. In one course on translation from Finnish into English, some students expressed their frustration with the need to increase textual cohesion and adapt somewhat obscurely written Finnish STs into a clearer information structure. The instructor explained these textual differences between the Finnish and the Anglo-American culture in terms of a different conceptualization of respecting the reader: if a Finnish text would over-explain a matter, it would be seen as an insult to the reader's intelligence, whereas a maxim of clarity and explicitness in Anglo-American texts would be seen as respect for the reader's time and effort. In class discussions, some students (in a class where all but the instructor were Finnish) subsequently began to conceptualize the $\mathrm{TT}$ recipient as a caricature of the simple American. It may be assumed that similar (albeit hopefully more constructive) discussions are a daily occurrence in almost any institution providing translation education and training, and these discussions could be analysed according to the social representations of ST authors and TT readers that are constructed and disseminated in education. Educational discourse would also provide an interesting site for studying the need to conceptualize ST authors and TT readers; thus, we could examine not only the spread of certain conceptualizations (the content of the social representations) but the processes of conceptualizing (the cognitive mechanisms discussed).

Sociogenetic processes among translators could also be studied with more product-oriented approaches (see Saldanha \& O'Brien, 2013). In this case, researchers could investigate the ways in which translators in certain language pairs tend to treat different knowledge systems: If the logical registers between source and target cultures differ, which one is privileged? Researchers could also investigate the ways in which certain translation solutions reflect potential social representations about ST authors and TT readers: Which elements are 
Hokkanen, S. (2020). Social representations theory: An approach to studying translators' sociocognitive processes. Linguistica Antverpiensia, New Series: Themes in Translation Studies, 19, 94-110.

censored or modified in anticipation of different affective responses in TT readers (Koskinen, 2012) and what does this reveal about the translators' social representations of them?

This latter line of enquiry has many similarities with an approach in translation research known as imagology (van Doorslaer et al., 2016). Imagological studies focus on national representations evident in translations and derive their methods largely from comparative literature. Imagology aims to deconstruct ethnotypes as they are manifested in texts, traditionally in literary genres, and to investigate what happens to them in translation. Such textual analysis of translations, combined with the contextual and cultural analysis that is typical of imagological studies, could also be employed in studies on the social representations of ST authors and TT readers, since it would provide insight into the sociogenetic processes that leave their traces in translated texts.

In addition to taking cognitive polyphasia into account at the sociogenetic level, the concept also has important implications at the ontogenetic level. As mentioned previously, not only do social groups have diverse social representations, but individuals can also employ multiple logical registers simultaneously, understand certain social objects in more than one way, or experience conflicting affects about them. Furthermore, individuals may be more conscious of some of these registers, understandings, or affects than others, so that direct questions about social representations rarely capture the full picture (Flick \& Foster, 2008). If, for example, translators are asked in an interview about how they conceptualize ST authors or $\mathrm{TT}$ readers (either in general or in relation to a specific text), they are prompted to reflect on their conceptualization, which will reveal something about how they verbalize and justify their cognitive processing in an interview situation (see also Wagner et al., 2000); but it will probably reveal little about the unconscious, often figurative elements of social representations (Marková, 1996).

Because social representations operate at multiple levels of human consciousness, it is usually necessary to use a variety of empirical methods in their investigation (Flick \& Foster, 2008; Marková, 1996). Some suggested ways of tapping into the more unconscious levels of social representations at the ontogenetic level include visual methods (e.g., drawing tasks) and word-association methods where participants are asked to list individual words they associate with a key word or phenomenon (Flick \& Foster, 2008; Moliner \& Abric, 2015). Other suggested approaches include interview methods in which participants either freely construct narratives about the phenomenon under study (e.g., narrative interviews; see Given, 2008) or are prompted to recount key episodes in their life related to the phenomenon (e.g., episodic interviews; see Flick, 2014). Interviewees' narrative or episodic accounts usually contain implied meanings that would be difficult to verbalize directly, but they can be scrutinized for the more tacit and taken-for-granted elements in participants' social representations.

The ontogenetic study of social representations usually focuses not only on individuals but also on how their social representations change over time (Duveen \& Lloyd, 1990). For the study of translators' conceptualizations of ST authors and TT readers, it might prove illuminating to investigate the changes in these social representations in longitudinal studies 
Hokkanen, S. (2020). Social representations theory: An approach to studying translators' sociocognitive processes. Linguistica Antverpiensia, New Series: Themes in Translation Studies, 19, 94-110.

that follow certain individuals along their educational and professional trajectories. Such longitudinal studies seem rather rare in our field (Liu, 2017), and if studies do follow the same individuals, the study period does not necessarily extend beyond a few years (Kujamäki, 2019; Liu, 2017; see, however, Hansen, 2013). In a study on social representations regarding ST authors and TT readers, the study period would ideally extend from the beginning of translation students' education - which has been shown to be a formative time for at least some professional skills (Hansen, 2013)-well into their professional careers, potentially following changes in places of work, work communities, and job descriptions. This would illuminate the way in which cognitive processes are moulded by individuals socializing into new environments, since "the social world has a fundamental impact on not only what we think but, crucially, how we think" (Voelklein \& Howarth, 2005, p. 437 [original emphasis]).

In addition to investigating changes in translators' social representations over a longer period, it might also be fruitful to examine more sudden transformations or enduring conflicts in their representational processes, for example, during a single translation task. These could be studied by using pre- and post-task interviews, ethnographic observation, or think-aloud protocols. Such task-specific studies may reveal, on the one hand, how the act of translation as a knowledge encounter (Jovchelovitch, 2007) may change what translators think about their ST authors and TT readers, which logical registers they use while doing so, and which affective responses they have towards these people or the groups they represent (Jovchelovitch \& Priego-Hernández, 2015). On the other hand, it might be interesting to investigate the lingering conflicts between these different components of translators' social representations of ST authors and TT readers (cf. Voelklein \& Howarth, 2005).

The level of microgenesis has been posited as the starting point for studying intergroup processes (Gillespie, 2012; see also Flick \& Foster, 2008), and this resonates clearly with situated and embodied approaches to translation cognition (e.g., Muñoz Martín, 2010; Risku, 2010). For example, Muñoz Martín (2010, p. 176) points out that in order to create meaning, speakers "build, blend, and use concepts" on the basis of "very similar bodily experiences, and they also modify these concepts constantly through social interaction, mainly thanks to the social tool of language". Similarly, Risku (2010) draws attention to the embodied and socially situated nature of cognition and argues that it leads to the necessity of studying translation practices in situ, with methods such as ethnography that allow for the analysis of participants' interactions in their social and material surroundings (see also Risku et al., 2019). The view expressed by Moscovici (1961/2008) that "there is no definite break between the outside world and the world of the individual (or group)" (p. 8), which underlies Social Representations Theory, therefore shares common ground with current thinking in Cognitive Translation Studies.

\section{Conclusions}

The aim of this article was to suggest that Social Representations Theory could be fruitfully applied to the study of translators' socio-cognitive processes. An example case referred to in the article was translators' conceptualizations of ST authors and TT readers. The basic concepts used in the theory were introduced and suggestions were offered on how the theory 
Hokkanen, S. (2020). Social representations theory: An approach to studying translators' sociocognitive processes. Linguistica Antverpiensia, New Series: Themes in Translation Studies, 19, 94-110.

could be applied in Cognitive Translation Studies. As the discussion indicated, the theory provides "conceptual richness" (Bauer \& Gaskell, 1999, p. 163) and an overarching model of socio-cognitive processes that is compatible with situated and embodied approaches to cognition.

The potential contribution of the theory to Cognitive Translation Studies is, I would argue, the fact that it provides Translation Studies scholars with a comprehensive theoretical model for studying the social construction of knowledge. It directs attention not only at individuals (ontogenesis) but also at social groups (sociogenesis) and at the social interaction and embodied actions (microgenesis) that link individuals to their social surroundings. Therefore, studies informed by the theory should be able to see the construction and reconstruction of knowledge as a dynamic process embedded in specific social and material environments. Social representations theory therefore promotes a move away from empirical applications that treat knowledge as intra-individual, static, and conscious mental structures-a view that is widely discarded in cognitive research (see, e.g., Barsalou, 1999; Muñoz Martín, 2010)and towards more holistic approaches to translators' socio-cognitive processes.

While this article discussed the potential of social representations theory to help in the study of translators' socio-cognitive processes, the discussion drew mainly on assumptions and hypothesizing, leaving the empirical verification of how-and whether-the theory is applicable to Cognitive Translation Studies for later work. However, a previous study by Leanza et al. (2017), focusing on the conceptualizations of users of public-service interpreting, points to the usefulness of the theory in the study of interpreting as a socially situated practice. Indeed, the social character of the human mind is ingrained in the theory, and it would therefore benefit researchers interested in the way translators' cognition is fundamentally moulded by their social and material surroundings.

\section{Acknowledgments}

I am grateful to the two anonymous reviewers for their helpful suggestions and to Mary Nurminen for commenting on several drafts of this manuscript.

\section{References}

Barsalou, L. W. (1999). Perceptual symbol systems. Behavioral and Brain Sciences, 22(4), 577-660. https://doi.org/10.1017/S0140525X99002149

Bauer, M. W., \& Gaskell, G. (1999). Towards a paradigm for research on social representations. Journal for the Theory of Social Behaviour, 29(2), 163-186. https://doi.org/10.1111/1468-5914.00096

Campbell, C., \& Jovchelovitch, S. (2000). Health, community and development: Towards a social psychology of participation. Journal of Community \& Applied Social Psychology, 10(4), 255-270. https://doi.org/10.1002/1099-1298(200007/08)10:4<255::AID-CASP582>3.0.CO;2-M

Carugati, F. F. (1990). From social cognition to social representations in the study of intelligence. In G. Duveen \& B. Lloyd (Eds.), Social representations and the development of knowledge (pp. 126143). Cambridge University Press. https://doi.org/10.1017/CBO9780511659874.008

Clark, A., \& Chalmers, D. (1998). The extended mind. Analysis, 58(1), 7-19. https://doi.org/10.1093/ analys $/ 58.1 .7$ 
Hokkanen, S. (2020). Social representations theory: An approach to studying translators' sociocognitive processes. Linguistica Antverpiensia, New Series: Themes in Translation Studies, 19, 94-110.

Duveen, G. (2000). Introduction: The power of ideas. In S. Moscovici \& G. Duveen (Eds.), Social representations: Explorations in social psychology (pp. 1-17). Polity Press.

Duveen, G., \& Lloyd, B. (1990). Introduction. In G. Duveen \& B. Lloyd (Eds.), Social representations and the development of knowledge (pp. 1-10). Cambridge University Press. https://doi.org/10.1017/ CBO9780511659874.001

Flick, U. (1995). Social representations. In J. A. Smith, R. Harré, \& L. Van Langenhove (Eds.), Rethinking psychology (pp. 70-96). SAGE.

Flick, U. (2014). An introduction to qualitative research (5th ed.). SAGE.

Flick, U., \& Foster, J. (2008). Social representations. In C. Willig \& W. Stainton-Rogers (Eds.), The SAGE handbook of qualitative research in psychology (1st ed., pp. 195-214). SAGE. http://dx.doi.org/ $10.4135 / 9781848607927$

Flick, U., Foster, J., \& Caillaud, S. (2015). Researching social representations. In G. Sammut, E. Andreouli, G. Gaskell, \& J. Valsiner (Eds.), The Cambridge handbook of social representations, (pp. 64-80). Cambridge University Press. https://doi.org/10.1017/CBO9781107323650.007

Gibbs, R. W. (2005). Embodiment and cognitive science. Cambridge University Press. https://doi.org/10.1017/CBO9780511805844

Gillespie, A. (2012). Concluding comment: Contact without transformation: The context, process and content of distrust. In I. Marková \& A. Gillespie (Eds.), Trust and conflict: Representation, culture and dialogue (pp. 201-216). Routledge.

Given, L. M. (Ed.). (2008). The SAGE encyclopedia of qualitative research methods. SAGE. http://dx. doi.org/10.4135/9781412963909

Goodwin, C. (1994). Professional vision. American Anthropologist, 96(3), 606-633. https://doi.org/10. 1525/aa.1994.96.3.02a00100

Hansen, G. (2013). Many tracks lead to the goal: A long-term study on individual translation styles. In C. Way, S. Vandepitte, R. Meylaerts, \& M. Bartłomiejczyk (Eds.), Tracks and treks in translation studies: Selected papers from the EST congress, Leuven 2010 (pp. 49-62). John Benjamins. https://doi.org/10.1075/btl.108.03han

Jodelet, D. (1991). Madness and social representations (G. Duveen, Ed., \& T. Pownall, Trans.). Harvester Wheatsheaf. (Original work published 1989)

Jovchelovitch, S. (2007). Knowledge in context: Representations, community and culture. Routledge. https://doi.org/10.4324/9780203968895

Jovchelovitch, S., \& Priego-Hernández, J. (2015). Cognitive polyphasia, knowledge encounters and public spheres. In G. Sammut, E. Andreouli, G. Gaskell, \& J. Valsiner (Eds.), The Cambridge handbook of social representations (pp. 163-178). Cambridge University Press. https://doi.org/10.1017/CBO9781107323650.014

Jääskeläinen, R. (2012). Translation psychology. In Y. Gambier \& L. van Doorslaer (Eds.), Handbook of translation studies (Vol. 3, pp. 191-197). John Benjamins. https://doi.org/10.1075/hts.3.tra14

Kruger, H., \& Kruger, J.-L. (2017). Cognition and reception. In J. W. Schwieter \& A. Ferreira (Eds.), The handbook of translation and cognition (pp. 71-89). Wiley-Blackwell. https://doi.org/10.1002/ 9781119241485.ch4

Koskinen, K. (2012). Domestication, foreignization and the modulation of affect. In H. Kemppanen, M. Jänis, \& A. Belikova (Eds.), Domestication and foreignization in translation studies (pp. 13-32). Frank \& Timme.

Kujamäki, M. (2019). Source text influence in student translation: Results of a longitudinal study. The Interpreter and Translator Trainer, 13(4), 390-407. https://doi.org/10.1080/1750399X.2019. 1615166

Lakoff., G., \& Johnson, M. (1980). Metaphors we live by. The University of Chicago Press. 
Hokkanen, S. (2020). Social representations theory: An approach to studying translators' sociocognitive processes. Linguistica Antverpiensia, New Series: Themes in Translation Studies, 19, 94-110.

Leanza, Y., Rizkallah, E., Michaud-Labonté, T., \& Brisset, C. (2017). From concern for patients to a quest for information: How medical socialization shapes family physicians' representations of interpreters. Interpreting, 19(2), 232-259. https://doi.org/10.1075/intp.19.2.04lea

Liu, C.F.-M. (2017). A longitudinal study of translators in greater China. Hermèneus, 19, 121-138. https://doi.org/10.24197/her.19.2017.121-138

Marková, I. (1996). Towards an epistemology of social representations. Journal for the Theory of Social Behaviour, 26(2), 177-196. https://doi.org/10.1111/j.1468-5914.1996.tb00528.x

Marková, I. (2012). Introduction: Conflict and trust in dialogical perspective. In I. Marková \& A. Gillespie (Eds.), Trust and conflict: Representation, culture and dialogue (pp. 1-14). Routledge. https://doi.org/10.4324/9780203806265

Moliner, P., \& Abric, J.-C. (2015). Central core theory. In G. Sammut, E. Andreouli, G. Gaskell, \& J. Valsiner (Eds.), The Cambridge handbook of social representations, (pp. 83-95). Cambridge University Press. https://doi.org/10.1017/CBO9781107323650.009

Moscovici, S. (1973). Foreword. In C. Herzlich (Ed.), Health and illness: A social psychological analysis (pp. IX-XIV). Academic Press.

Moscovici, S. (1984). The phenomenon of social representations. In R. M. Farr \& S. Moscovici (Eds.), Social representations (pp. 3-69). Cambridge University Press.

Moscovici, S. (1988). Notes towards a description of social representations. European Journal of Social Psychology, 18(3), 211-250. https://doi.org/10.1002/ejsp.2420180303

Moscovici, S. (2008). Psychoanalysis: Its image and its public (G. Duveen, Ed., \& D. Macey, Trans.). Polity Press. (Original work published 1961)

Muñoz Martín, R. (2010). On paradigms and cognitive translatology. In G. M. Shreve \& E. Angelone (Eds.), Translation and cognition (pp. 169-187). John Benjamins. https://doi.org/10.1075/ata.xv. 10 mun

Muñoz Martín, R. (2016). Processes of what models?: On the cognitive indivisibility of translation acts and events. Trans/ation Spaces, 5(1), 145-161. https://doi.org/10.1075/ts.5.1.08mun

Nord, C. (2012). Quo vadis, functional translation? Target, 24(1), 26-42. https://doi.org/10.1075/ target.24.1.03nor

O'Connor, C. (2017). Embodiment and the construction of social knowledge: Towards an integration of embodiment and social representations theory. Journal for the Theory of Social Behaviour, 47(1), 2-24. https://doi.org/10.1111/jtsb.12110

Risku, H. (2010). A cognitive scientific view on technical communication and translation: Do embodiment and situatedness really make a difference? Target, 22(1), 94-111. https://doi.org/10.1075/target.22.1.06ris

Risku, H., Rogl, R., \& Milosevic, J. (Eds.). (2019). Translation practice in the field. John Benjamins. https://doi.org/10.1075/bct.105

Saldanha, G., \& O'Brien, S. (2013). Research methodologies in translation studies. Routledge. https://doi.org/10.4324/9781315760100

Sammut, G., Andreouli, E., Gaskell, G., \& Valsiner, J. (Eds.) (2015). The Cambridge handbook of social representations. Cambridge University Press. https://doi.org/10.1017/CBO9781107323650

Smith, N. W., \& Joffe, H. (2009). Climate change in the British press: The role of the visual. Journal of Risk Research, 12(5), 647-663. https://doi.org/10.1080/13669870802586512

Suojanen, T., Koskinen, K., \& Tuominen, T. (2015). User-centered translation. Routledge. https://doi. org/10.4324/9781315753508

van Doorslaer, L., Flynn, P., \& Leerssen, J. (Eds.). (2016). Interconnecting translation studies and imagology. John Benjamins. https://doi.org/10.1075/btl.119 
Hokkanen, S. (2020). Social representations theory: An approach to studying translators' sociocognitive processes. Linguistica Antverpiensia, New Series: Themes in Translation Studies, 19, 94-110.

Voelklein, C., \& Howarth, C. (2005). Review of controversies about social representations theory: A British debate. Culture \& Psychology, 11(4), 431-454. https://doi.org/10.1177/1354067X050585 $\underline{86}$

Wagner, W. (2015). Representation in action. In G. Sammut, E. Andreouli, G. Gaskell, \& J. Valsiner (Eds.), The Cambridge handbook of social representations, (pp. 12-28). Cambridge University Press. https://doi.org/10.1017/CBO9781107323650.004

Wagner, W. (2017). Embodied social representation. Journal for the Theory of Social Behaviour, 47(1), 25-31. https://doi.org/10.1111/itsb.12113

Wagner, W., Duveen, G., Farr, R., Jovchelovitch, S., Lorenzi-Cioldi, F., Marková, I., \& Rose, D. (1999). Theory and method of social representations. Asian Journal of Social Psychology, 2(1), 95-125. https://doi.org/10.1111/1467-839X.00028

Wagner, W., Duveen, G., Verma, J. \& Themel, M. (2000). 'I have some faith and at the same time I don't believe': Cognitive polyphasia and cultural change in India. Journal of Community \& Applied Social Psychology, 10(4), 301-314. https://doi.org/10.1002/1099-1298(200007/08)10:4<301:: AID-CASP585>3.0.CO;2-V 